would require the calculation of scale weights for each item following the methods outlined by Patrick. ${ }^{10}$ Finally, the index is comprehensive, covering aspects of the patients' physical, emotional, and social problems.

In the light of these comments the index should be tested in as wide a range of settings as possible. While the method has been developed for assessing elderly patients with arthritis of the hip, it may be reasonable to test it on patients with other locomotor disorders. The additional information provided by the method should be valuable in planning the best course of treatment and in assessing the extent of progress made. This may be of particular value where, as with knee replacement operations, the prognosis is less certain than with hip replacement operations.

We thank Jan Lindsay, Dee Nelson, Evelyn Papp, Jan Williams, and Margaret Barton for their unstinting help. The research was supported by grant No HR 3607-1 from the Social Sciences Research Council, London.

\section{References}

1 Wood, P H N, Proceedings of the Royal Society of London, 1976, 192, 131.

2 British Medical fournal, 1975, 2, 296.

3 Larson, C B, Clinical Orthopaedics and Related Research, 1963, 31, 85.

${ }^{4}$ Shepherd, M M, fournal of Bone and foint Surgery, 1960, 42B, 177.

${ }^{5}$ Harris, W H, Fournal of Bone and foint Surgery, 1969, 51A, 737.

${ }^{6}$ Melzack, R, Pain, 1975, 1, 277.

${ }^{7}$ Elinson, J, International fournal of Health Services, 1976, 6, 385.

${ }^{8}$ Harris, A, Handicapped and Impaired in Great Britain, $\mathrm{p} 2$. London, HMSO, 1971.

${ }^{9}$ Sackett, D L, et al, American fournal of Public Health, 1977, 67, 423.

10 Patrick, D L, International fournal of Health Services, 1976, 6, 443.

(Accepted 28 fuly 1978)

\title{
Screening for impaired visual acuity in middle age in general practice
}

\author{
DAVID H STONE, DAVID J SHANNON
}

British Medical fournal, 1978, 2, 859-863

\section{Summary and conclusions}

Screening for impaired distant visual acuity was one component of a controlled trial of multiphasic screening in middle age carried out in two general practices. The prevalence of impaired visual acuity $(6 / 18$ or worse in the better eye) at the initial screening in 1967 was $9.6 \%$ overall, ranging from $5.9 \%$ in people aged $40-49$ years to $16.3 \%$ in those aged over 60. The question "Do you have difficulty seeing distant objects?" had a low sensitivity and high specificity, rendering it unsatisfactory for use in mass population screening for visual impairment. The prevalences of impaired visual acuity in the screening and control groups at the survey in 1972 showed no significant differences in any age group.

Mass screening for defects of visual acuity in the course of a multiphasic examination is thus unlikely to reduce the prevalence of impaired distant visual acuity in the community.

\section{Introduction}

In summing up a series of papers Holland ${ }^{1}$ suggested that screening might be more effectively aimed at identifying people with conditions such as disorders of vision that are amenable to alleviation rather than prevention or cure. Since 1967 a longterm study of multiphasic screening in middle age has been in progress in south London, ${ }^{2}$ and screening for impaired visual

\footnotetext{
Department of Community Medicine, St Thomas's Hospital Medical School, London

DAVID H STONE, MRCP, lecturer (present address: Greater Glasgow Health Board, 351 Sauchiehall Street, Glasgow G2 3HT)

DAVID J SHANNON, MSC, lecturer (present address: Computer and Statistics Department, Pfizer (Central Research), Sandwich, Kent CT139NJ)
}

acuity was one component of the programme. The study therefore presented an opportunity to test Holland's hypothesis, as well as providing previously unavailable data on the prevalence of defective visual acuity in a middle-aged population.

\section{Methods}

The design and methodology of the south-east London screening study has been reported in detail elsewhere. ${ }^{3}$ Briefly, all people $(n=7229)$ aged 40-64 years who were registered in 1967 with two south London general practices were identified and randomly allocated into one of two groups, designated screening and control. The screening group $(\mathrm{n}=3297)$ was invited by letter to attend an evening screening clinic at which a series of questions was asked and clinical tests carried out. Two years later this group was invited to a second, similar screening clinic. The control group $(n=3353)$ was not asked to either of these sessions. In 1972 both groups were invited to take part in a health survey so that direct comparisons of their clinical states could be made. The questions asked at the screening included: "Do you have difficulty in seeing distant objects (with spectacles if you have them) ?" and "Do you normally wear glasses for distant vision ?" The former question was self-administered and the latter asked by the interviewer.

Distant visual acuity was measured by using a standard Snellen card at six metres in moderate artificial lighting. Each eye was tested separately, with lens correction if available. The responses to the questions and the results of the tests were recorded, coded, punched on cards, and stored for analysis. The attention of the general practitioner was drawn to any abnormal result so that he might decide whether more definitive diagnosis or treatment (or both) was indicated.

\section{Results}

In this analysis impaired visual acuity was defined according to the criteria of the World Health Organisation-that is, as $6 / 18$ or worse in the better eye, both eyes using best correction. ${ }^{4}$ The response rate at the initial screening was $73.4 \%$, rising to $82.4 \%$ at the survey, for which more intensive efforts were made to contact non-responders. Response rates have previously been described in detail. ${ }^{5}$ Table I shows the prevalence $(9.6 \%)$ of impaired visual acuity found at the initial screening in 1967 . There was a trend towards poorer visual acuity with age. No difference was found between the sexes. Table II shows the presence of a social-class gradient, people in social class $\mathrm{V}$ 
having double the prevalence of impaired visual acuity of those in social class I. This effect was independent of age. The question "Do you have difficulty seeing distant objects (with spectacles if you have them) ?" was answered positively by $9 \cdot 1 \%$ of the population. The ability of the question to identify people who when tested had impaired visual acuity was poor (sensitivity $=28.4 \%$ ), though it successfully identified those with normal visual acuity (specificity $=92.9 \%$; table III).

At the 1972 survey no significant differences were found in the prevalences of impaired visual acuity between the screening and control groups (table IV). The age gradient was still present, but no social-class trend was evident. Because the response rate was higher at the 1972 survey than at the initial screening in 1967 we were able to examine the prevalence of impaired visual acuity in those who refused

TABLE I-Numbers (\%) of people with normal and impaired visual acuity at initial screening (WHO criteria) according to age

\begin{tabular}{|c|c|c|c|}
\hline \multirow{2}{*}{ Age in years } & \multicolumn{2}{|c|}{ Visual acuity } & \multirow{2}{*}{ Total } \\
\hline & Normal & Impaired* & \\
\hline $\begin{array}{l}40-49 \\
50-59 \\
60-64\end{array}$ & $\begin{array}{r}1130(94.1) \\
785(87.9) \\
273(83.7)\end{array}$ & $\begin{array}{r}71(5 \cdot 9) \\
108(12 \cdot 1) \\
53(16 \cdot 3)\end{array}$ & $\begin{array}{r}1201(100 \cdot 0) \\
893(100 \cdot 0) \\
326(100 \cdot 0)\end{array}$ \\
\hline All ages & $2188(90 \cdot 4)$ & $232(9 \cdot 6)$ & $2420(100 \cdot 0)$ \\
\hline
\end{tabular}

* $6 / 18$ or worse in better eye.

TABLE II-Social-class distribution of people with normal and impaired visual acuity. Figures are numbers (\%) of people

\begin{tabular}{l|r|r|r}
\hline \multirow{2}{*}{ Social class } & \multicolumn{2}{|c|}{ Visual acuity } & \multicolumn{1}{|c}{ Total } \\
\cline { 2 - 3 } & \multicolumn{1}{|c|}{ Normal } & \multicolumn{1}{|c}{ Impaired } & \\
\hline II & $64(91 \cdot 4)$ & $6(8 \cdot 6)$ & $70(100 \cdot 0)$ \\
II & $260(95 \cdot 2)$ & $13(4 \cdot 8)$ & $273(100 \cdot 0)$ \\
IV & $1269(90 \cdot 8)$ & $129(9 \cdot 2)$ & $1398(100 \cdot 0)$ \\
V & $443(88 \cdot 8)$ & $56(11 \cdot 2)$ & $499(100 \cdot 0)$ \\
\hline All classes & $137(83 \cdot 0)$ & $28(17 \cdot 0)$ & $165(100 \cdot 0)$ \\
\hline & $2173(90 \cdot 4)$ & $232(9 \cdot 6)$ & $2405(100 \cdot 0)$ \\
\hline
\end{tabular}

TABLE III-Validation" of question "Do you have difficulty seeing distant objects (with spectacles if you have them)?"Figures are numbers (\%) of people

\begin{tabular}{|c|c|c|c|}
\hline \multirow{3}{*}{$\begin{array}{c}\begin{array}{c}\text { Response } \\
\text { to question }\end{array} \\
\begin{array}{l}\text { Yes } \\
\text { No }\end{array} \\
\end{array}$} & \multicolumn{2}{|c|}{ Visual acuity (tested) } & \multirow{2}{*}{ Total } \\
\hline & Impaired & Normal & \\
\hline & $\begin{array}{rr}65 & (28.4) \\
164 & (71.6)\end{array}$ & $\begin{array}{rr}154 & (7 \cdot 1) \\
2011 & (92 \cdot 9) \\
\end{array}$ & $\begin{array}{rr}219 & (9 \cdot 1) \\
2175 \quad(90 \cdot 9)\end{array}$ \\
\hline Total & $229(100 \cdot 0)$ & $2165(100 \cdot 0)$ & $2394(100 \cdot 0)$ \\
\hline
\end{tabular}

*Sensitivity $=28.4 \%$; specificity $=92.9 \%$.

TABLE IV-Numbers (\%) of people with normal and impaired visual acuity in screening and control groups at 1972 survey

\begin{tabular}{|c|c|c|c|c|}
\hline \multirow{2}{*}{ Age in years } & \multicolumn{2}{|c|}{ Screening group* } & \multicolumn{2}{|c|}{ Control group } \\
\hline & Normal & Impaired & Normal & Impaired \\
\hline $\begin{array}{l}40-49 \\
50-59 \\
60-64\end{array}$ & $\begin{array}{l}493(93.9) \\
803(88 \cdot 5) \\
494(83 \cdot 4)\end{array}$ & $\begin{array}{r}32(6 \cdot 1) \\
104(11 \cdot 5) \\
98(16 \cdot 6)\end{array}$ & $\begin{array}{l}487(93 \cdot 1) \\
804(89 \cdot 4) \\
487(84 \cdot 0)\end{array}$ & $\begin{array}{l}36(6.9) \\
95(10 \cdot 6) \\
93(16 \cdot 0)\end{array}$ \\
\hline All ages & $1790(88.4)$ & $234(11 \cdot 6)$ & $1778(88 \cdot 8)$ & $224(11 \cdot 2)$ \\
\hline
\end{tabular}

*Includes those who refused to take part in initial screening.

TABLE $\mathrm{v}-$ Number (\%) of people who refused to take part in initial screening having normal and impaired visual acuity at 1972 survey

\begin{tabular}{|c|c|c|c|}
\hline \multirow{2}{*}{ Age in years } & \multicolumn{2}{|c|}{ Visual acuity } & \multirow{2}{*}{ Total } \\
\hline & Normal & Impaired & \\
\hline $\begin{array}{l}40-49 \\
50-59 \\
60-64\end{array}$ & $\begin{array}{r}63(90 \cdot 0) \\
119(90 \cdot 2) \\
119(86.9)\end{array}$ & $\begin{array}{r}7(10 \cdot 0) \\
13(9 \cdot 8) \\
18(13 \cdot 1)\end{array}$ & $\begin{array}{r}70(100 \cdot 0) \\
132(100 \cdot 0) \\
137(100 \cdot 0)\end{array}$ \\
\hline All ages & $301(88 \cdot 8)$ & $38(11 \cdot 2)$ & $339(100 \cdot 0)$ \\
\hline
\end{tabular}

TABLE VI-Number (\%) of people wearing spectacles at 1972 survey according to age and sex

\begin{tabular}{|c|c|c|c|c|}
\hline $\begin{array}{c}\text { Age } \\
\text { in years }\end{array}$ & Sex & $\begin{array}{l}\text { Spectacles } \\
\text { worn }\end{array}$ & $\begin{array}{l}\text { Spectacles } \\
\text { not worn }\end{array}$ & Total \\
\hline $\begin{array}{l}40-49 \\
50-59 \\
60-64\end{array}$ & $\begin{array}{l}\mathrm{M} \\
\mathrm{F} \\
\mathrm{M} \\
\mathrm{F} \\
\mathrm{M} \\
\mathrm{F}\end{array}$ & $\begin{array}{l}115(30 \cdot 8) \\
162(29 \cdot 2) \\
321(43 \cdot 0) \\
400(49 \cdot 5) \\
282(57 \cdot 8) \\
334(72 \cdot 9)\end{array}$ & $\begin{array}{l}258(69 \cdot 2) \\
392(70 \cdot 8) \\
425(57 \cdot 0) \\
408(50 \cdot 5) \\
206(42 \cdot 2) \\
124(27 \cdot 1)\end{array}$ & $\begin{array}{l}373(100 \cdot 0) \\
554(100 \cdot 0) \\
746(100 \cdot 0) \\
808(100 \cdot 0) \\
488(100 \cdot 0) \\
458(100 \cdot 0)\end{array}$ \\
\hline All ages & $\begin{array}{l}\mathrm{M} \\
\mathrm{F}\end{array}$ & $\begin{array}{l}718(44 \cdot 7) \\
896(49 \cdot 2)\end{array}$ & $\begin{array}{l}889(55 \cdot 3) \\
924(50 \cdot 8)\end{array}$ & $\begin{array}{l}1607(100 \cdot 0) \\
1820(100 \cdot 0)\end{array}$ \\
\hline
\end{tabular}

TABLE VII-Number (\%) of patients in screening (including those who refusedscreening) and control groups who wore spectacles at the 1972 survey

\begin{tabular}{|c|c|c|c|c|c|}
\hline & & \multicolumn{2}{|c|}{ Men } & \multicolumn{2}{|c|}{ Women } \\
\hline & & $\begin{array}{l}\text { Screening } \\
\text { group }\end{array}$ & $\begin{array}{l}\text { Control } \\
\text { group }\end{array}$ & $\begin{array}{l}\text { Screening } \\
\text { group }\end{array}$ & $\begin{array}{c}\text { Control } \\
\text { group }\end{array}$ \\
\hline $\begin{array}{l}\text { Wore spectacles } \\
\text { No spectacles ... }\end{array}$ & $\begin{array}{l}\cdots \\
\cdots\end{array}$ & $\begin{array}{ll}362 & (45 \cdot 4) \\
435 & (54 \cdot 6)\end{array}$ & $\begin{array}{ll}356 & (44 \cdot 0) \\
454 & (56 \cdot 0) \\
\end{array}$ & $\begin{array}{ll}442 & (50 \cdot 0) \\
442 & (50 \cdot 0) \\
\end{array}$ & $\begin{array}{ll}454 & (48.5) \\
482 & (51.5)\end{array}$ \\
\hline Total & & $797(100 \cdot 0)$ & $810(100 \cdot 0)$ & $884(100 \cdot 0)$ & $936(100 \cdot 0)$ \\
\hline
\end{tabular}

screening but attended the survey. Table $\mathrm{V}$ shows that, although the numbers were small, the prevalences were similar to those in thes screened population.

The prevalence of spectacle wearing was examined at the survey Overall, $47 \%$ of the population stated that they normally wore spectacles for distant vision. A pronounced increase in spectacle wearing with age was apparent (table VI). There were no significant differences in the prevalences of spectacle wearing in the screening and control groups by sex or age (table VII).

\section{Discussion}

Screening for visual disorders is usually concerned with the early detection of strabismus and amblyopia in children and glaucoma in adults. This paper describes one of the few attempto to detect and treat defects of distant visual acuity in middle-aged people. Visual impairment was present in $9.6 \%$ of the screene population by the WHO definition. Since attending a screening clinic may be a social task of considerable complexity for the most severely handicapped members of the community the were probably underrepresented in the screened population The above figure may therefore underestimate the true prevalence. The rising prevalence of defective visual acuity with age was not surprising, since many of the common cause of impaired vision (cataract, macular degeneration, etc) are associated with aging. The social-class distribution found at the initial screening was consistent with the findings of the United States national health survey ${ }^{6}$; its subsequent disappearance ato the 1972 survey is puzzling.

A screening question that fails to detect cases of impairmen $\tilde{P}$ as dismally as "Do you have difficulty in seeing distant objects ?'W is patently unsuitable for use in mass screening. The higt specificity of the question does not compensate for this. In survey of visual impairment in Kent, Cullinan found that the question "Are you able to recognise a friend over the road?"? had a sensitivity of $64 \%$ and a specificity of $48 \%$ when validate against the same criteria. ${ }^{7}$ It therefore appears that sucto questions cannot be substituted for testing sight in any screening programme that is to be satisfactory.

The participants' poor subjective assessment of their visua $\mathbb{P}$ acuity may have implications for driving-licence policy in the United Kingdom. According to Department of Transpore criteria a visual acuity of $6 / 18$ or worse in the better eye repre sents, unequivocally, unfitness to drive. ${ }^{8}$ While the proportion of drivers in the sample is unknown, the results of this study raise questions about the effectiveness of current procedures in identifying the substantial proportion of middle-aged people 
whose visual acuity falls short of the legal requirement. After taking the driving test, which includes reading car numberplate letters at a fixed distance, a driver is obliged to notify the Vehicle Licensing Centre as soon as he becomes aware that his vision has deteriorated below the specified standard. On the evidence presented here, most middle-aged people with impaired distant visual acuity are unaware of their disability, a finding that casts doubt on the adequacy of existing legislation.

The slightly higher overall prevalence of visual impairment at the 1972 survey reflected the aging of the whole population over the five years. The lack of significant difference in the prevalence of impaired visual acuity between the screening and control groups suggests that screening had no measurable impact on distance vision. The explanation for this disappointing result probably lies in the multiphasic nature of the screening programme. A large volume of data was presented to each person's general practitioner, who was expected to assess the clinical importance of abnormal findings and, if necessary, arrange further investigation, treatment, and follow-up. Previously reported analyses have shown that the general practitioners initiated treatment for only a few of the abnormalities discovered at screening. ${ }^{2}$ In future studies of multiphasic screening it would be advisable either to reduce the scale of the examinations, concentrating on perhaps one or two systems, or to provide sufficient additional resources to exploit fully the yield of clinical information.

Finally, nearly half the study population claimed to wear spectacles for distant vision. This is five times the proportion found to have impaired distant vision on testing. Unless most of this lens correction is unnecessary spectacle wearing apparently limits the prevalence of impaired visual acuity in the community. More investigation is needed to establish whether improved quality or frequency of optical prescription would reduce it still further. Hopes that mass screening might fulfil such a role have not been realised.

We are indebted to Professor W W Holland and colleagues in the department of community medicine, St Thomas's Hospital Medical School, for their advice and encouragement ; to Dr H J T Woodall and Dr E Tuckman, without whose help the study could not have taken place; and to the Department of Health and Social Security, who partly supported the south-east London screening study.

\section{References}

${ }^{1}$ Holland, W W, Lancet, 1974, 2, 1494

2 South-east London Screening Group, International fournal of Epidemio$\log y, 1977,6,357$.

${ }^{3}$ Trevelyan, H, Preventive Medicine, 1973, 1, 278.

4 World Health Organisation, The Prevention of Blindness, WHO Technical Report Series No 518. Geneva, WHO, 1973.

5 D'Souza, M F, Swan, A V, and Shannon, D J, Lancet, 1976, 1, 1228.

${ }^{6}$ Guralnick, L, Vital and Health Statistics, 1967, series 3, No 7.

7 Cullinan, T, The Epidemiology of Visual Impairment (Part 2). Canterbury, Health Services Research Unit, University of Kent, 1976.

8 Department of Transport of the Department of the Environment, Leafle LF 676. Crowthorne, Transport and Road Research Laboratory, 1977.

(Accepted 24 fuly 1978)

\title{
Effect of cirrhosis of the liver on the pharmacokinetics of chlormethiazole
}

\author{
P J PENTIKÄINEN， P J NEUVONEN， S TARPILA， E SYVÄLAHTI
}

British Medical fournal, 1978, 2, 861-863

\section{Summary and conclusions}

The pharmacokinetics of chlormethiazole were studied in eight patients with advanced cirrhosis of the liver and in six healthy volunteers after oral and intravenous administration of the drug. In the patients the systemic bioavailability of oral chlormethiazole was increased about tenfold, whereas its elimination was only slightly retarded. The increased bioavailability was clearly due to decreased first-pass metabolism of chlormethiazole in the cirrhotic liver.

The results indicate that chlormethiazole should be used in reduced dosage when given by mouth to patients with cirrhosis of the liver.

University of Helsinki, Helsinki, Finland

P J PENTIKÄINEN, MD, senior lecturer, second department of medicine P J NEUVONEN, MD, senior lecturer, department of clinical pharmacology $S$ TARPILA, MD, senior lecturer, second department of medicine

Medical Department, Astra Läkemedel, Södertälje, Sweden E SYVÄLAHTI, MD, senior lecturer

\section{Introduction}

Chlormethiazole is a derivative of the thiazole part of vitamin $B_{1}$, and owing to its sedative-hypnotic and anticonvulsant properties it is widely used for treating restlessness and agitation -for example, in delirium tremens. Although chlormethiazole is thought to be relatively safe, several deaths have been described in association with its use, mostly after excessive dosage..$^{1-4}$ Impaired liver function has been considered as a possible risk factor for chlormethiazole toxicity. ${ }^{3}$ Chlormethiazole is eliminated mainly by metabolism, only a very small amount being excreted unchanged in the urine. Furthermore, oral chlormethiazole undergoes extensive first-pass metabolism, which may be dose-dependent. ${ }^{5-7}$ In view of these properties of chlormethiazole changes could be expected to occur in its pharmacokinetics in patients with cirrhosis of the liver.

We have evaluated the absorption and elimination of chlormethiazole in patients with advanced cirrhosis of the liver and in a group of healthy volunteers.

\section{Subjects and methods}

Eight men with biopsy-proved alcoholic cirrhosis of the liver participated in the study. Laparoscopy with liver biopsy had been performed two to six months before. All had a history of alcohol abuse but abstained from alcohol for at least one month before the study. They had no other significant diseases. Six healthy male volunteers 